\title{
Efficiency of Numerical Images Analysis in Selection of Durum Wheat [Triticum turgidum (L.) ssp. durum (Desf.) Husn.] Genotypes Growing under Semi-arid Conditions in Algeria
}

\author{
Benalia Frih ${ }^{1}$, Abdelmalek Oulmi', Ali Guendouz ${ }^{2}$
}

10.18805/ag.DF-398

\begin{abstract}
Background: This study was conducted during the 2020/2021 cropping season at Setif Agricultural Experimental Station, it aims to assess the efficiency of using numerical image analysis (NIA) in the selection of durum wheat genotypes in semi-arid areas.

Methods: The genetic materials used in this study consist of 11 advanced lines and 4 genotypes of which 3 are local landraces used as control to evaluate their performance, the genotypes tested were sown in a randomized block design (RDB) with three replications. each plot consisted of 6 lines of $10 \mathrm{~m}$ long spaced of $0.2 \mathrm{~m}$ witdth makes $12 \mathrm{~m}^{2}$ as plot area.

Result: Analysis of variance showed that all the parameters measured numerically (senescence and total reflectance) had a very high genotypic significance. The chlorophyll content at full heading showed a very highly significant genotypic effect. Thousand kernels weight, number of spikes per meter square, number of days to heading and plant height had a significant genotypic effect. The correlation study showed that all senescence parameters were significantly correlated. A significant and negative correlation was observed between chlorophyll contents; average of velocity and total reflectance. Grain yield was highly and significantly correlated with thousand kernels weight and number of spikes per meter square. Number of spikes per meter square was significantly and positively correlated with average of velocity and negatively correlated with sum of temperatures at mid-senescence. Number of days to heading was significantly and negatively correlated with senescence average and maximum of senescence average. A significant correlation was observed between plant height and sum of temperatures at mid-senescence.

Key words: Chlorophyll contents, Durum wheat, Grain yield, Reflectance, Semi-arid, Senescence.
\end{abstract}

\section{INTRODUCTION}

Durum wheat [Triticum turgidum L. ssp. durum (Desf.) Husn.] is the $10^{\text {th }}$ most important crop worldwide with an annual production of over 40 million tons (Sall et al., 2019).The largest producer is the European Union, with 9 million tonnes in 2018, followed by Canada, Turkey, United States, Algeria, Mexico, Kazakhstan, Syria and India (Tedone et al., 2018). Durum wheat [Triticum turgidum (L.) ssp. durum (Desf.) Husn.] is one of the most cultivated cereals in the Mediterranean basin, where drought is a limiting factor for its production. (Royo et al., 1998), it's mostly grown under rain-fed conditions, where drought and heat stress usually constrain yield potential during the grain filling period (Simane et al., 1993).

Senescence is a universal phenomenon in living organisms and the word senescence has been used by scientists working on a variety of systems, such as yeast, fruit fly, worm, human being and plants. However, the meaning of the word senescence to scientists working on different organisms can be different and the difference can be subtle in some cases and very obvious in some other cases (Hafsi and Guendouz, 2012). Senescence is subject to strong environmental and genetic regulation and prior to visual yellowing and chlorosis up to $50 \%$ of leaf chlorophyll may be lost (Buchanan-Wollaston et al., 2005; Borrill et al., 2019). Photosynthesis is the primary source of dry matter production and grain yield in crop
1Department of Biology and Plant Ecology, VRBN Laboratory, Farhat Abbas Sétif University 1, Algeria.

${ }^{2}$ National Institute of Agronomic Research of Algeria (INRAA), Sétif Unit, Algeria.

Corresponding Author: Benalia Frih, Department of Biology and Plant Ecology, VRBN Laboratory, Farhat Abbas Sétif University 1, Algeria. Email: benaliafrih@gmail.com

How to cite this article: Frih, B., Oulmi, A. and Guendouz, A. (2022). Efficiency of Numerical Images Analysis in Selection of Durum Wheat [Triticum turgidum (L.) ssp. durum (Desf.) Husn.] Genotypes Growing under Semi-arid Conditions in Algeria. Agricultural Science Digest. DOI: 10.18805/ag.DF-398.

Submitted: 27-08-2021 Accepted: 02-12-2021 Online: 06-01-2022 plants, the improvements of leaf photosynthesis have occurred with the advance of breeding high-yielding cultivars (Jiang et al., 2002).

The breeding of new cereal grain varieties requires methods that are rapid and preferably non-destructive, to assess the quality of grain in early generations. Near infrared (NIR) spectroscopy has great potential to meet these requirements for the durum wheat breeder (Sisons et al., 2006). Our study aim to test the efficiency of the use of flag leaf senescence parameters, total reflectance and the chlorophyll contents as selection criteria for durum wheat genotypes growing under semi-arid conditions. 
Efficiency of Numerical Images Analysis in Selection of Durum Wheat [Triticum turgidum (L.) ssp. durum (Desf.) Husn.]...

\section{MATERIALS AND METHODS}

The study site

This study was conducted during the 2020/2021 cropping season at Setif Agricultural Experimental Station (ITGC-AES, $36^{\circ} 12^{\prime} \mathrm{N}$ and $05^{\circ} 24^{\prime} \mathrm{E}$ and $1.081 \mathrm{~m}$ asl, Algeria).

\section{Plant material}

The genetic material used in this study consists of 11 advanced lines and 4 genotypes of which 3 are local landraces and used as control to evaluate the performance of the experimental material (Table 1).

\section{Experimental device}

The genotypes tested were sown at November 19 with sowing density adjusted to 300 grains $\mathrm{m}^{-2}$ in a randomized block design (RBD) with three replications. Each plot consisted of 6 lines of $10 \mathrm{~m}$ long spaced of $0.2 \mathrm{~m}$ width which makes $12 \mathrm{~m}^{2}$ as plot area.

\section{Parameters measured}

The following parameters were measured:

\section{Physiologic traits}

\section{Sénescence parameters : (Sa\%;Vsa; Vmax; $\left.\sum \mathrm{T}_{50 \mathrm{~s}}\right)$}

We have followed the evolution of leaf senescence during 13 dates of assessment from flowering until $100 \%$ of leaf senescence (S1-S13) by Numerical Image Analysis (NIA) according to Guendouz and Maamri (2011), Leaves were photographed on black surface, between 11:00 and 12:00 solar time with a color digital camera (Canon, Power Shot A460, AiAF, CHINA). Images were stored in a JPEG (Joint Photographic Expert Group) prior to downloading onto a PC computer and analyzed using IPP (Image Pro Plus, Version 4, Media Cybernetics, Silver Spring, MA, USA) software. The percentage of senescence (S) was calculated foreach date of observation and for each genotype studied using Digimizer software (Fig 1) by calculating the percentage of senescent zone from the total of leaf surface $\mathrm{S}(\%)=$ (senescent area of flag leaf/flag leaf area)*100 (S1-S13). The 13 dates of assessment will be expressed subsequently in cumulative temperatures $\Sigma \mathrm{T}^{\circ} \mathrm{C}\left(\sum 1-\sum 13\right)$. In the base of these values the following parameters were calculated:

a. Average of senescence $\mathrm{Sa}(\%)$ : is the average of the following percentage of senescence in the following dates

$$
\mathrm{Sa} \%=(\mathrm{S} 1+\mathrm{S} 2 \ldots \ldots \mathrm{Sn}) / \mathrm{n}
$$

$\mathrm{n}=$ number of dates

b. Average of velocity Vsa $\left(\% /{ }^{\circ} \mathrm{C}\right)$ :

- The velocity of senescence (Vs) was calculated every date of senescence values

$$
V s=\left(S_{n+1}-S_{n}\right) /\left(\sum T C_{n+1}-\sum T C_{n}\right)
$$

$\Sigma T C=$ Sum of temperatures in the date of senescence value - Average of velocity $V s a$ is the average of the following velocity of the following dates

$$
\mathrm{Vsa}=(\mathrm{Vs} 1+\mathrm{Vs} 2 \ldots . . \mathrm{Vsn}) / \mathrm{n}
$$

c. Maximum of the senescence velocity (Vmax): is the highest velocity unregistered.

d. Sum of temperatures at mid-senescence $\left(\sum \mathrm{T}_{50 \mathrm{~s})}\right.$ : estimated from the curve:

$\mathrm{S}=\mathrm{f}\left(\sum \mathrm{T}^{\circ} \mathrm{C}_{\mathrm{s}}\right)(\mathrm{Fig} 2)$ as the sum of temperatures corresponding to $S=50 \%$.

\section{Total reflectance: $R(t)$ (at full heading)}

With the same images (using to calculate senescence), we calculate reflectance using Mesurim_pro_02 software (Guendouz and Maamri, 2011), this software can measure the reflectance at Red, Blue, Green band and total reflectance. We used the total reflectance for our work (Fig 3).

\section{Chlorophyll contents CC (at full heading)}

Chlorophyll contents (CC) of the flag leaf was measured using digital chlorophyll meter (CCM) with (cci) units, this device allows measuring the absorbance of light in the leaf.

Table 1: Varieties and their pedigrees.

\begin{tabular}{ll}
\hline Genotype & Pedigrees \\
\hline G1 & RASCON_37/GREEN_2/9/USDA595/3/D67.3/RABI//CRA/4/ALO/5/... \\
G2 & MINIMUS_6/PLATA_16//MMER/3/SOOTY_9/RASCON_37/9/... \\
G3 & CMH77.774/CORM//SOOTY-9/RASCON-37/3/SOMAT-4 \\
G4 & CNDO/PRIMADUR//HAI-OU-17/3/SNITAN/4/SOMAT-3/ \\
G5 & RASCON_37/GREEN_2/9/USDA595/3/D67.3/RABI//CRA/4/ALO/5/... \\
G6 & SILVER 14/MOEWE//BISU_I/PATKA_3/3/PORRON_4/YUAN_//9/... \\
G7 & GUANAY /HU ALITA / 10/PLATA_10/6/MQUE/4/USDA573/... \\
G8 & BCRIS/BICUM//LLARETA INIA/3/DUKEM_12/2*RASCON 21/5/R \\
G9 & Simeto/3/Sora/2*Plata_12//SRN_3/Nigris_4/5/Toska_26/... \\
G10 & Ossl1/StjS5/5/Bicrcderaal/4/BEZAIZSHF//SD19539/Waha/3/St \\
G11 & Stj3//Bcr/Lks4/3/Ter-3/4/MgnI3/Aghrass2 \\
G12 & Jupare C 2001 \\
G13 & Boussellem \\
G14 & Boutaleb \\
G15 & Oued Bared \\
\hline
\end{tabular}




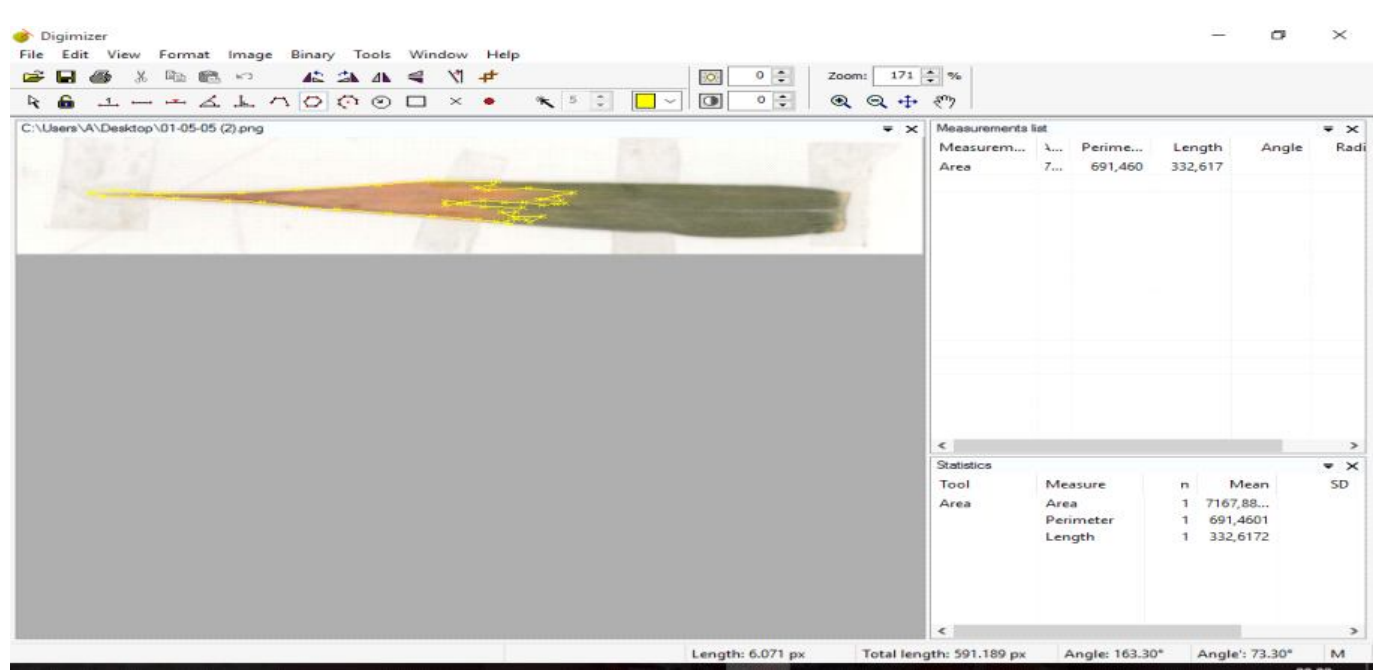

Fig 1: Estimation of senescence by Digimizer software.

\section{Agronomic traits (at maturity)}

\section{Grain yield (GY)}

The cereal yield performances of the different cultivars were measured at maturity in quintals per hectare (Qs. ha ${ }^{-1}$ ) by measuring the grain yield in one linear meter and converting it into quintals per hectare. Thousand kernels weight (TKW) (g). Number of spikes per meter square $\left(\mathrm{NSm}^{-2}\right)$. Number of days to heading $(\mathrm{DH})$ (days) calculated from sown date 19/ 11/2020. Plant height $(\mathrm{PH}) \mathrm{cm}$.

\section{Data analysis}

All statistical analyses will be performed by Costat 6.400 (1998) software.

\section{RESULTS AND DISCUSSION}

\section{Analysis of variance (ANOVA)}

\section{Agronomic traits}

ANOVA (Table 2) showed that genotypic effect was significant $(p<0.05 ; 0.001)$ with Thousand Kernels Weight (TKW), number of spikes per meter square, days to heading and Plant Height $(\mathrm{PH})$. Grain Yield average ranged from 2.87 Q.ha-1 for G11 to 13.59 Q.ha-1 for Boutaleb with genotypic mean of 6.34 Q.ha $^{-1}$. Thousand kernels weight arranged from $30.91 \mathrm{~g}$ for $\mathrm{G} 8$ to $46.69 \mathrm{~g}$ for $\mathrm{G} 9$ with $39.40 \mathrm{~g}$ as genotypic mean. Comparing to general mean, high values of TKW was observed with the local landraces Boutaleb (44.96 g). NSm${ }^{-2}$ ranged from 178.33 s.m ${ }^{-2}$ for $\mathrm{G} 4$ to 320 s.m $\mathrm{m}^{-2}$ for Boutaleb with a genotypic mean of $255.77 \mathrm{~s} . \mathrm{m}^{-2}$. The number of days to heading ranged from 136 days for advanced lines G1, G2, G8, G10 and Jupare C 2001 to 147 for Boutaleb local landrace with 140.6 as genotypic mean. Plant height ranged from $56.11 \mathrm{~cm}$ for $\mathrm{G} 4$ to $67.38 \mathrm{~cm}$ for $\mathrm{G} 10$ with a mean of 62.76 , local landrace Boutalebregistered a high plant height $(66.16 \mathrm{~cm})$.

\section{Physiologic traits}

For all genotypes studied, the senescence function with sums of temperatures after flowering was of sigmoid type.
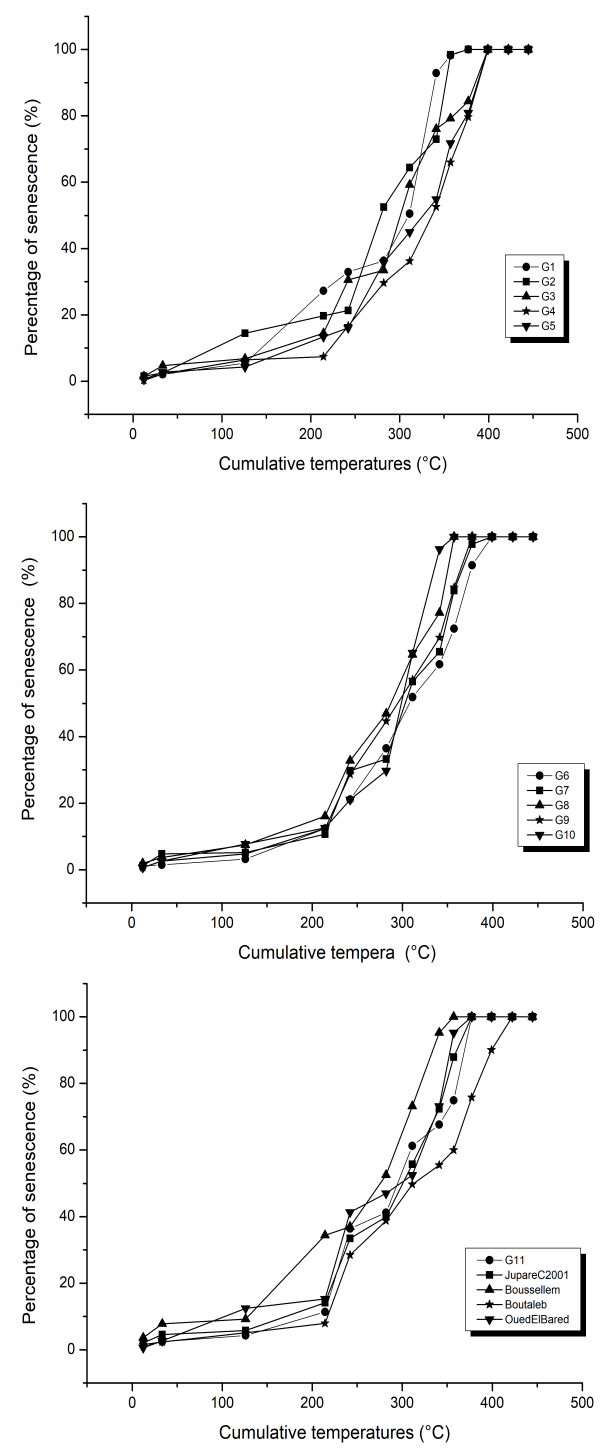

Fig 2: Senescence functions with sums of temperatures after flowering of the 15 genotypes studied. 
Efficiency of Numerical Images Analysis in Selection of Durum Wheat [Triticum turgidum (L.) ssp. durum (Desf.) Husn.]...

$\sum \mathrm{T} 50_{s}$ the sums of temperatures corresponding to $\mathrm{S}=50 \%$ (mid-senescence) differed markedly amongst genotypes, as shown in (Fig 2). ANOVA showed that genotype effect was highly significant $(P<0.001)$ with all senescence parameters calculated Sa; Vsa; Vmax and $\Sigma \mathrm{T} 50_{\mathrm{s}}$, total reflectance $\mathrm{R}(\mathrm{t})$ and chlorophyll contents at full heading (Table 3 ). Senescence average ( $\mathrm{Sa}$ ) ranged from $29.68 \%$ for advanced line $\mathrm{G} 4$ to $44.76 \%$ for advanced line $\mathrm{G} 2$ with genotypic mean of $38.76 \%$. Average of velocity (Vsa) arranged from $0.319 \% /{ }^{\circ} \mathrm{C}$ for $\mathrm{G} 3$ to $0.429 \% /{ }^{\circ} \mathrm{C}$ for Boussellem with a genotypic mean of $0.379 \% /{ }^{\circ} \mathrm{C}$.Vmaxranged from $0.792 \% /{ }^{\circ} \mathrm{C}$ for Boutaleb to
$1.593 \% /{ }^{\circ} \mathrm{C}$ for $\mathrm{G} 2$ with genotypic mean of $1.139 \% /{ }^{\circ} \mathrm{C}$. $\sum \mathrm{T} 50_{\mathrm{s}}$ arranged from $276.44^{\circ} \mathrm{C}$ for Bousselem to $337.13^{\circ} \mathrm{C}$ for $\mathrm{G} 4$ with genotypic mean of $302.25^{\circ} \mathrm{C}$. The local landrace Boutaleb witch was the best yielding genotype registered the low Sa\% (32.49\%), a low value of $\mathrm{Vs} \%$ parameter $\left(0.347 \% /{ }^{\circ} \mathrm{C}\right)$, a low value of $\operatorname{Vmax}\left(0.792 \% /{ }^{\circ} \mathrm{C}\right)$ and a high value of $\sum \mathrm{T} 50_{\mathrm{s}}\left(311.91^{\circ} \mathrm{C}\right)$ comparing to genotypic means. The genotypes with lowest values of senescence average (Sa\%) and highest values of sum of temperatures at mid-senescence were the most tolerant and adapted genotypes (Hafsi and Guendouz, 2020). At full heading, R

Table 2: Analysis of variance of agronomic traits.

\begin{tabular}{|c|c|c|c|c|c|}
\hline \multirow{2}{*}{ Genotypes } & \multicolumn{5}{|c|}{ Agronomic traits } \\
\hline & GY (Qs.ha-1) & TKW (g) & $\mathrm{NSm}^{-2}$ & DH (days) & $\mathrm{PH}(\mathrm{cm})$ \\
\hline G1 & $7.00(\mathrm{bc})$ & 41.98 (bc) & 236.66 (bcde) & $136(d)$ & $62.72(\mathrm{~cd})$ \\
\hline G2 & $3.96(\mathrm{bc})$ & 35.62 (ef) & 213.33 (de) & $136(d)$ & $61.50(d)$ \\
\hline G3 & $7.05(\mathrm{bc})$ & $40.83(\mathrm{bcd})$ & 220.00 (cde) & 142 (c) & $61.88(d)$ \\
\hline G4 & $2.88(\mathrm{c})$ & 36.80 (de) & $178.33(\mathrm{e})$ & 142 (c) & $56.11(\mathrm{e})$ \\
\hline G5 & $4.70(\mathrm{bc})$ & $36.10(e)$ & 220.00 (cde) & 142 (c) & $61.27(d)$ \\
\hline G6 & $6.16(\mathrm{bc})$ & $31.88(\mathrm{fg})$ & 240.00 (bcde) & 142 (c) & $61.27(d)$ \\
\hline G7 & 6.89 (bc) & 34.36 (efg) & 253.33 (abcde) & 142 (c) & $57.66(\mathrm{e})$ \\
\hline G8 & $4.45(\mathrm{bc})$ & $30.91(\mathrm{~g})$ & $268.33(\mathrm{abcd})$ & $136(d)$ & $61.16(d)$ \\
\hline G9 & $6.61(\mathrm{bc})$ & $46.69(a)$ & $310.00(a b)$ & 142 (c) & $65.55(a b c)$ \\
\hline G10 & $8.69(a b)$ & 41.98 (bc) & 268.33 (abcd) & $136(d)$ & $67.38(a)$ \\
\hline G11 & $2.95(c)$ & 44.47 (abc) & $285.00(a b c d)$ & 142 (c) & $67.22(a)$ \\
\hline Jupare C 2001 & 7.89 (bc) & $41.98(\mathrm{bc})$ & $255.00(\mathrm{abcd})$ & $136(d)$ & $63.61(\mathrm{bcd})$ \\
\hline Boussellem & $4.75(\mathrm{bc})$ & $40.39(\mathrm{~cd})$ & $291.66(a b c)$ & $142(c)$ & $63.94(\mathrm{bcd})$ \\
\hline Boutaleb & 13.59 (a) & $44.96(a b)$ & 320.00 (a) & 147 (a) & $66.16(a b)$ \\
\hline Oued El Bared & $7.59(\mathrm{bc})$ & $43.27(\mathrm{abc})$ & $276.66(\mathrm{abcd})$ & 146 (b) & $63.88(\mathrm{bcd})$ \\
\hline Mean & 6.34 & 39.40 & 255.77 & 140.6 & 62.76 \\
\hline Min & 2.87 & 30.91 & 178.33 & 136 & 56.11 \\
\hline Max & 13.59 & 46.69 & 320 & 147 & 67.38 \\
\hline Génotype effect & ns & $* * *$ & * & $* * *$ & $* * *$ \\
\hline $\operatorname{LSD}_{(5 \%)}$ & 5.672 & 4.162 & 76.53 & 1.526 & 3.167 \\
\hline CV \% & 53.45 & 6.30 & 17.89 & $6.4901 \mathrm{e}-8$ & 3.017 \\
\hline
\end{tabular}

ns: Non-significant; *: Significant $(P<0.05)$; Very highly significant $(P<0.001)$.

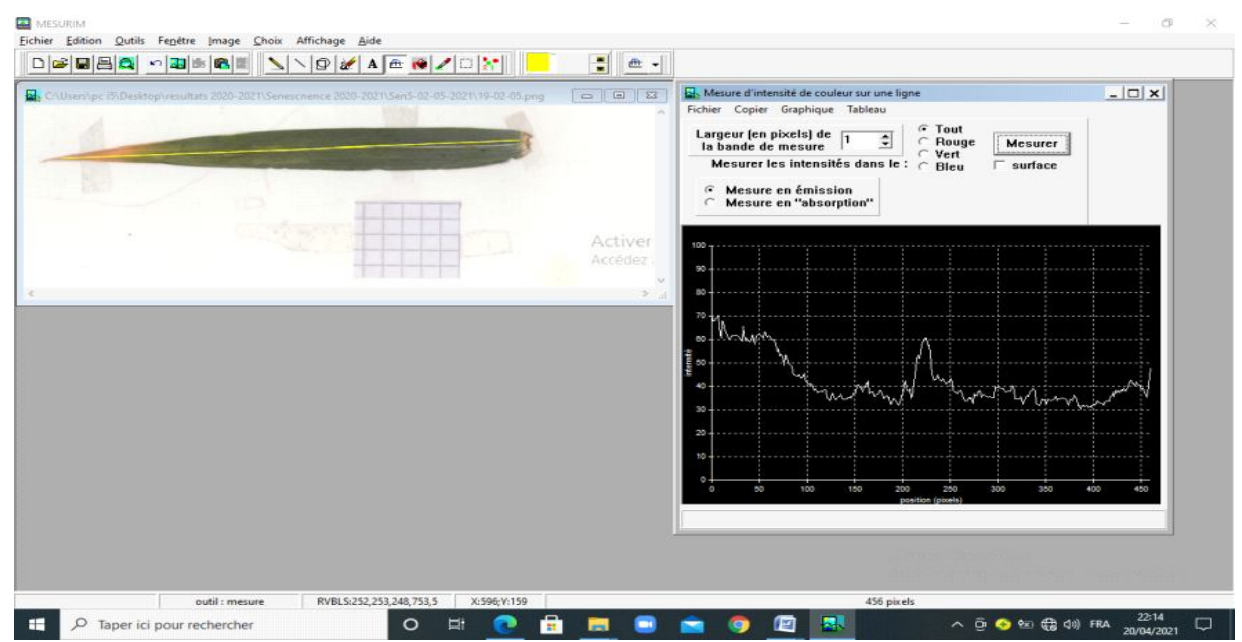

Fig 3: Reflectance calculating in total band using Mesurim_pro_02 software. 
Efficiency of Numerical Images Analysis in Selection of Durum Wheat [Triticum turgidum (L.) ssp. durum (Desf.) Husn.]...

(t) was ranged from $32.74 \%$ for $\mathrm{G} 7$ to $40.77 \%$ for $\mathrm{G} 3$ with genotypic mean of $36.37 \%$, Boutalebregistered a low value of $\mathrm{R}(\mathrm{t})(35.85 \%)$ comparing to mean. Chlorophyll content was ranged from $26.65 \mathrm{cci}$ for Oued El Bared to $40.81 \mathrm{cci}$ for G4 with genotypic mean of 33.05 cci. The diversity of the yield is a consequence of the variation of the duration rather than the variation of the rate of the photosynthetic activity; the delay of the senescence is a good parameter of selection of the cereals which must be followed (Hafsi et Guendouz, 2020).

\section{Correlations among traits}

\section{Correlations among agronomic traits}

The study of the correlations among agronomic traits (Table 4) showed that grain yield was high significantly $(P<0.01 ; 0.001)$ and positively correlated with thousand kernels weight and number of spikes per meter square $\left(r=0.38^{* *} ; 0.61^{* * *}\right)$. A high and significant $(P<0.01 ; 0.001)$ and positive correlation was observed between thousand kernels weight and number of spikes per meter square and plant height $\left(r=0.39^{* *}\right.$; $\left.0.61^{* * *}\right)$. Number of spikes per meter square was significantly $(\mathrm{P}<0.05)$ and positively correlated with plant height $\left(r=0.34^{*}\right)$. Several works have proven the high correlation between grain yield and some agronomic traits (Guendouz et al., 2012; Aissaoui and Fenni, 2021 and Mansouri et al., 2018).

\section{Correlations among physiologic traits}

The study of the correlations among senescence parameters (Table 3 ) showed that senescence average (Sa) was highly and significantly $(p<0.01 ; 0.001)$ correlated with average of Velocity of senescence (Vsa) and maximum of Velocity (Vmax) $\left(r=0.47^{* *} ; 0.73^{* * *}\right.$ respectively) and very highly and negatively correlated with sum of temperatures at $50 \%$ of senescence $\left(\sum T 50 s\right)\left(r=-0.74^{* * *}\right)$. Velocity of senescence average (Vsa) was significantly $(p<0.01 ; 0.001)$ correlated with maximum of velocity $\left(r=0.40^{* *}\right)$ and negatively correlated with sum of temperatures at mid-senescence and Total reflectance $R(t)\left(r=-0.63^{* * *} ;-0.39^{* *}\right)$. Reflectance at total band $R(t)$ was significantly $(P<0.05)$ and negatively correlated with chlorophyll contents $\left(r=-0.35^{\star}\right)$, the decrease of leaf reflectance increase the photosynthetic capacity of leaves by increasing radiations absorbed by chlorophyll pigments (Guendouz and Hafsi, 2016). Chlorophyll tends to decline more rapidly than carotenoids when plants are under stress or during leaf senescence (Gitelson and Merzlyak, 1994).

\section{Correlation among physiologic and agronomic traits}

Days to heading was high significantly $(p<0.01)$ and negatively correlated with senescence average and maximum of velocity $\left(r=-0.38^{* *}, r=-0.41^{* *}\right)$ this results imply that precocity increases senescence rate, velocity average

Table 3: Analysis of variance of physiologic traits.

\begin{tabular}{|c|c|c|c|c|c|c|}
\hline \multirow{2}{*}{ Genotypes } & \multicolumn{4}{|c|}{ Sénescence parameters } & \multirow{2}{*}{$\begin{array}{c}\text { Total reflectance } \\
\mathrm{R}(\mathrm{t})(\%) \\
\end{array}$} & \multirow{2}{*}{$\begin{array}{c}\text { Chlorophyll contents } \\
\text { CC (cci) }\end{array}$} \\
\hline & $\mathrm{Sa}(\%)$ & Vsa $\left(\% /{ }^{\circ} \mathrm{C}\right)$ & $\operatorname{Vmax}\left(\% /{ }^{\circ} \mathrm{C}\right)$ & $\sum \mathrm{T} 50_{\mathrm{s}}\left({ }^{\circ} \mathrm{C}\right)$ & & \\
\hline $\mathrm{G} 1$ & $44.66(b)$ & $0.327(\mathrm{~m})$ & $1.412(b)$ & 310.37 (c) & 36.87 (c) & 29.00 (de) \\
\hline G2 & $44.76(\mathrm{a})$ & $0.382(h)$ & $1.593(\mathrm{a})$ & 278.97 (i) & $38.73(b)$ & $30.18(\mathrm{de})$ \\
\hline G3 & $39.03(\mathrm{~g})$ & $0.319(\mathrm{n})$ & 0.887 (i) & 301.72 (ef) & 40.77 (a) & 30.21 (de) \\
\hline G4 & $29.68(I)$ & $0.335(\mathrm{I})$ & $0.837(\mathrm{j})$ & $337.73(a)$ & $36.84(\mathrm{c})$ & 40.81 (a) \\
\hline G5 & $32.52(k)$ & $0.348(k)$ & $1.059(f)$ & 327.69 (b) & $36.45(\mathrm{~cd})$ & 29.71 (de) \\
\hline G6 & $35.32(\mathrm{j})$ & 0.370 (i) & $0.954(\mathrm{gh})$ & 307.4 (d) & 35.63 (def) & 31.40 (cde) \\
\hline G7 & $38.83(h)$ & $0.405(f)$ & $1.149(\mathrm{e})$ & $302.72(e)$ & $32.74(\mathrm{~g})$ & $37.73(a b)$ \\
\hline G8 & $38.95(\mathrm{~g})$ & $0.403(\mathrm{~g})$ & $1.425(b)$ & $288.47(h)$ & 35.98 (cde) & 32.15 (cde) \\
\hline G9 & $40.53(\mathrm{e})$ & $0.415(e)$ & $0.941(\mathrm{~h})$ & $295.14(\mathrm{~g})$ & 36.17 (cde) & $36.12(\mathrm{abc})$ \\
\hline G10 & 37.31 (i) & 0.357 (j) & $1.041(f)$ & $299.81(f)$ & $34.93(f)$ & $33.83(\mathrm{bcd})$ \\
\hline G11 & $40.06(f)$ & $0.420(c)$ & $1.254(d)$ & $295.14(\mathrm{~g})$ & 35.71 (def) & $35.90(a b c)$ \\
\hline Jupare C 2001 & $41.59(d)$ & 0.417 (d) & $0.975(\mathrm{~g})$ & $299.81(f)$ & 35.61 (def) & $38.16(a b)$ \\
\hline Boussellem & $41.65(d)$ & $0.429(a)$ & $1.380(\mathrm{c})$ & 276.44 (j) & 35.25 (ef) & $34.16(\mathrm{bcd})$ \\
\hline Boutaleb & $32.49(k)$ & $0.347(k)$ & $0.792(k)$ & $311.91(\mathrm{c})$ & 35.85 (def) & 29.66 (de) \\
\hline Oued El Bared & 44.02 (c) & $0.422(b)$ & $1.380(\mathrm{c})$ & $300.42(f)$ & $37.98(b)$ & $26.65(\mathrm{e})$ \\
\hline Mean & 38.76 & 0.379 & 1.139 & 302.25 & 36.37 & 33.05 \\
\hline Min & 29.68 & 0.319 & 0.792 & 276.44 & 32.74 & 26.65 \\
\hline Max & 44.76 & 0.429 & 1.593 & 337.73 & 40.77 & 40.81 \\
\hline Genotype effect & $* * *$ & $* * *$ & $* \star \star$ & $* * *$ & $* \star *$ & $* * *$ \\
\hline $\operatorname{LSD}_{(5 \%)}$ & 0.093 & 0.002 & 0.024 & 2.189 & 0.925 & 5.533 \\
\hline CV \% & 0.14 & 0.29 & 1.30 & 0.43 & 1.52 & 10.01 \\
\hline
\end{tabular}

***: Very highly significant $(\mathrm{P}<0.001)$. 
Efficiency of Numerical Images Analysis in Selection of Durum Wheat [Triticum turgidum (L.) ssp. durum (Desf.) Husn.]...

Table 4: Correlations among physiologic and agronomic traits.

\begin{tabular}{|c|c|c|c|c|c|c|c|c|c|c|c|}
\hline & $\mathrm{Sa}$ & Vsa & Vmax & "T50s & $R(t)$ & $\mathrm{CC}$ & GY & TKW & $\mathrm{NSm}^{-2}$ & $\mathrm{DH}$ & $\mathrm{PH}$ \\
\hline $\mathrm{Sa}$ & 1 & & & & & & & & & & \\
\hline Vsa & $0.47^{* *}$ & 1 & & & & & & & & & \\
\hline Vmax & $0.73^{* \star *}$ & $0.40^{* *}$ & 1 & & & & & & & & \\
\hline “T50s & $-0.74^{* * *}$ & $-0.63^{* * *}$ & $-0.61^{* * *}$ & 1 & & & & & & & \\
\hline$R(t)$ & 0.19 & $-0.39^{* *}$ & 0.07 & -0.01 & 1 & & & & & & \\
\hline $\mathrm{CC}$ & -0.22 & 0.19 & -0.28 & 0.11 & -0.35 * & 1 & & & & & \\
\hline GY & -0.05 & -0.13 & -0.28 & 0.05 & -0.04 & -0.02 & 1 & & & & \\
\hline TKW & 0.19 & 0.10 & -0.20 & -0.07 & 0.14 & -0.08 & $0.38^{* *}$ & 1 & & & \\
\hline $\mathrm{NSm}^{-2}$ & 0.14 & $0.35^{*}$ & -0.01 & $-0.30^{*}$ & -0.27 & 0.07 & $0.61^{* * *}$ & $0.39^{* *}$ & 1 & & \\
\hline $\mathrm{DH}$ & $-0.38^{* *}$ & 0.04 & $-0.41^{* *}$ & 0.29 & 0.02 & -0.12 & 0.18 & 0.28 & 0.20 & 1 & \\
\hline $\mathrm{PH}$ & 0.24 & 0.21 & 0.02 & $-034^{*}$ & 0.01 & -0.29 & 0.27 & $0.61^{* * *}$ & $0.35^{*}$ & 0.03 & 1 \\
\hline
\end{tabular}

*Significant $(\mathrm{P}<0.05)$; ${ }^{* *}$ Highly significant $(\mathrm{P}<0.01) ;{ }^{* * *}$ Very highly significant $(\mathrm{P}<0.001)$.

had a positive significance $(P<0.05)$ correlation with number of spikes per meter square $\left(r=0.35^{*}\right)$, sum of temperatures a mid-senescence was significantly $(P<0.05)$ and negatively correlated with number of spikes per meter square and plant height $\left(r=-0.30^{*} ;-0.34^{*}\right)$ (Table 4$)$. These results are relatively adequate with those of Guendouz et al.,(2013) who suggested more or less similar correlations with some agronomic traits.

\section{CONCLUSION}

This study confirms the efficiency of the use of flag leaf senescence,total reflectance and chlorophyll contents at full heading as selection criteria for durum wheat in semiarid areas using numerical image analysis (NIA). ANOVA showed that genotype effect was significant for thousand kernels weight, number of spikes per meter square, number of days to heading and plant height. Genotype effect were also significant for all senescence parameters, total reflectance and chlorophyll contents at full heading. The study of the correlations showed that grain yield was high significantly and positively correlated with thousand kernels weight and number of spikes per meter square, in addition all senescence parameters were significantly correlated. The negative correlation between chlorophyll contents and total reflectance at full heading suggest that the decrease of leaf reflectance increase the photosynthetic capacity of leaves by increasing radiations absorbed by chlorophyll pigments. The negative correlation between number of days to heading and senescence average and maximum of velocity implies that precocity increases senescence rate.

\section{Conflict of interest}

Authors declare that they have no conflict of interest.

\section{REFERENCES}

Aissaoui, M.R. and Fenni, M. (2021). Effect of supplemental irrigation on bread wheat genotypes yield under Mediterranean semi-arid conditions of north-eastern Algeria. Revista Facultad Nacional de Agronomía Medellín. 74(1): 9431-9440.
Borrill, P., Harrington S.A.,Simmonds, J. and Uauy, C. (2019). Identification of transcription factors regulating senescence in wheat through gene regulatory network modelling. Plant Physiology. 180(3): 1740-1755. http://dx.doi.org/ 10.1104/pp.19.00380.

Buchanan Wollaston, V., Page, T., Harrison, E., Breeze, E., OkLim, P., GilNam, H., Lin, J.F., Wu, S.H., Swidzinski, J., Ishizaki, K. and Leaver, C.J. (2005) .Comparative transcriptome analysis reveals significant differences in gene expression and signaling pathways between developmental and dark/ starvation-induced senescence in Arabidopsis. Plant Journal. 42(4): 567-585. http://dx.doi.org/10.1111/j.1365313X.2005.02399.x.

Costat 6.400, (1998). Copyright@1998-2008, CoHort Software798 Lighthouse Ave BMP 320, Montery, CA 93940, USA, Email: info@cohort.com, URL http://www.cohort.com.

Gitelson, A.A. and Merzlyak, M.N. (1994). Spectral reflectance changes associate with autumn senescence of Aesculus hippocastanum L. and Acer platanoides L. leaves. Spectral features and relation to chlorophyll estimation. Journal of Plant Physiology. 143: 286-292.

Guendouz, A. and Maamri, K. (2011). Research note evaluating durum wheat performance and efficiency of senescence parameter usage in screening under Mediterranean conditions. Electronic Journal of Plant Breeding. 2(3): 400-404.

Guendouz, A., Guessoum, S., Maamri, K. and Hafsi, M. (2012). The effect of supplementary irrigation on grain yield, yield components and some morphological traits of durum wheat (Triticum durum Desf.) cultivars. Advance in Environmental Biology. 6(2) : 564-572.

Guendouz, A., Guessoum, S., Maamri, K., Benidir, M. and Hafsi, M. (2013). Performance of ten durum wheat (Triticum durum Desf.) cultivars under semi arid conditions (North Africa -Algeria-). Indian Journal of Agricultural Research. 47(4): 317-322.

Guendouz, A. and Hafsi, M. (2016). Effect of supplementary irrigation on reflectance and some physiological properties of durum wheat (Triticum durum Desf.). Revue Agriculture. 12: 86-99.

Hafsi, M. and Guendouz, A. (2012). Some aspects of leaf senescence, senescence, Dr. Tetsuji Nagata (Ed.), ISBN: 978-953-510144-4, InTech, Available from: http://www.intechopen.com/ books/senescence/someaspects-of-leaf-senescence. 
Efficiency of Numerical Images Analysis in Selection of Durum Wheat [Triticum turgidum (L.) ssp. durum (Desf.) Husn.]...

Hafsi, M. and Guendouz, A. (2020). Leaf senescence in wheat: A drought tolerance measure, plant science - Structure, anatomy and physiology in plants cultured in vivo and in vitro, Ana Gonzalez, María Rodriguez and Nihal Gören Sağlam, IntechOpen, http://doi.org/10.5772/intechopen. 89500.

Jiang, H., Wang, X.H., Deng, Q.Y., Yuan, L.P. and Xu, D.Q. (2002). Comparison of some photosynthetic characters between two hybrid rice combinations differing in yield potential. Photosynthtica. 40: 133-137.

Mansour, A., Oudjehih, B., Benbelkacem, A., Fellahi, Z. and Bouzerzour, H. (2018). Variation and relationships among agronomic traits in durum wheat [Triticum turgidum (L.) Thell. ssp. Turgidum conv. Durum (Desf.) Mackey] under south mediterranean growth. International Journal of Agronomy Volume 2018, Article ID 8191749, 11 pages. https://doi. org/10.1155/2018/8191749.

Royo, C., Michelena, A., Carrillo, J.M., Garcýa, P., Juan -Aracil, J. and Soler, C. (1998). Spanish Durum Wheat Breeding Program. In: SEWANA (South Europe, West Asia and North Africa) Durum Research Network. [Nachit, M.M., Baum, M., Porceddu, Monneveux, Picard, E (eds)], Proceedings of the SEWANA Durum Network Workshop, 20-23 March 1995. ICARDA: Aleppo, Syria, pp 80-87.
Sall, A., Chiari, T., Legesse, W., Seid-Ahmed, K., Ortiz, R., van Ginkel, M. (2019). Durum wheat (Triticum durum Desf.): origin, cultivation and potential expansion in Sub-Saharan Africa. Agronomy 9:263. https://doi.org/10.3390/agronomy 9050263.

Simane, B., Struik, P.C., Nachit, M.M. and Peacock, J.M. (1993). Ontogenetic analysis of yield components and yield stability of durum wheat in water-limited environments. Euphytica. 71: 211-219.

Sissons, M., Osborne, B., Sissons, S. (2006). Application of near infrared reflectance spectroscopy to a durum wheat breeding programme. Journal of Near Infrared Spectroscopy. 14(1): 17-25. https://doi.org/10.1255\%2Fjnirs.582.

Tedone, L., Alhajj Ali, S., De Mastro, G. (2018). Optimization of Nitrogen in Durum Wheat in the Mediterranean Climate: The Agronomical Aspect and Greenhouse Gas (GHG) Emissions. In Nitrogen in Agriculture-Updates; [Amanullah, K., Fahad, S., (Eds.)]; InTech: London, UK; Volume 8, pp. 131-162. 